\title{
CFD Simulation of a Post-Compensated Load Sensing Directional Control Valve
}

\author{
Paola Fresia ${ }^{1}$ and Massimo Rundo ${ }^{1 *}$ \\ ${ }^{1}$ Department of Energy, Politecnico di Torino, C.so Duca degli Abruzzi 24, 10129, Turin, Italy
}

\begin{abstract}
The paper presents the CFD model of a load sensing directional control valve. The model was validated experimentally in terms of pressure drop and flow force at different positions of the spool. The spool position was imposed manually by means of a micrometric screw and a load cell was used for measuring the flow force. The CFD model was developed with the CADembedded tool FloEFD ${ }^{\circledR}$. The model has been proved to be very reliable in estimating the pressure drop, moreover quite good results were obtained also in the evaluation of the flow force. The CFD simulations were used to tune the coefficients of a lumped parameter model of the valve, so that such a model can be efficiently used for the simulation of an entire hydraulic circuit. Moreover, the CFD model has been used as design tool for attenuating the detrimental effect of the flow force. In particular, the width of the land upstream of the metering edge has an influence on the resultant force on the spool. If was found that it is possible to significantly reduce the flow force at maximum opening with a relatively small increment of the pressure drop across the valve.
\end{abstract}

\section{Introduction}

In mobile hydraulic systems used in many off-road vehicles, such as excavators, telehandlers or agricultural machines, the proportional directional control valves are the control elements for deciding the direction and the velocity of the actuators. Despite in the recent years the trend is to move towards valveless systems [1,2], most of the current machines still use a centralized hydraulic circuit with the load sensing principle [3-5]. Such a layout includes a variable displacement pump with a differential pressure control and a proportional valve with local compensator for each actuator. The position of the main spool of the proportional directional valves is controlled by an electro-hydraulic device or, in some recent applications, by a directacting electric linear motor. The force that the control device must exert to accelerate and to keep in position the spool must be high enough for counterbalancing the flow force, which is generated by the change of the fluid momentum and it tends to close the flow area. Since such a force is proportional to the flow rate, the control force must be considerable in high-size valves.

In this context it is important to have a simulation tool able to quantify the flow forces in a spool valve, so that it can be used for optimizing the geometry in order to minimize them. The lumped parameter models use a simplified formulation for the calculation of the flow force that can be suitable for simple geometries, but it could not consider more complex 3D effects on the

\footnotetext{
*Corresponding author: massimo.rundo@polito.it
} 
velocity and pressure fields. The alternative approach is to use a CFD model and for this aim different commercial tools are available.

Although in a load sensing valve the pressure compensator is a component whose position is not imposed but it depends on the equilibrium of the forces acting on it, for validating the reliability of the CFD code it is possible to study the case where all components are fixed, even if the movement of the compensator could be taken into account [6]. In a valve two important aspects must be considered: the internal pressure drops and the forces on the movable components. The minimization of the pressure drops [7] is aimed at reducing the dissipated power and the effectiveness can be easily verified experimentally. The simulation procedure can also be automated for finding the optimal internal geometry [8]. The simulation of the flow force could require a more detailed model, because it is necessary to calculate very accurately the entire pressure field all around the movable element and not only across the minimum flow area. Examples of calculation of the flow force on conical poppet valves are reported in the references [9-11], even if in these cases a direct measurement of the force is not possible. In case of spool valves the experimental measurement of the force acting on the moveable element is more feasible. A few studies are available in literature [12-15], where the outcomes from a CFD model built with ANSYS Fluent ${ }^{\circledR}$ are contrasted with the force values measured by means of a load cell. Instead in [16] the authors measured the torque on the spool and contrasted the results with a model developed in SimericsMP $+{ }^{\circledR}$.

In this paper a CFD model developed with FloEFD of a load sensing valve is presented. Both the pressure drop and the flow force have been simulated and measured in different operating conditions. The model can be efficiently used for tuning a lumped parameter model of the valve. Moreover, a modification of the spool has been proposed for reducing the flow force with an acceptable increment of the pressure drop.

\section{Component description}

The component analyzed in the present study is a post-compensated load sensing directional control valve used in multi-actuator mobile applications. With reference to Fig. 1, that shows a typical layout of a load sensing system for feeding two linear actuators, each module is made up of a main spool and a local compensator LC.

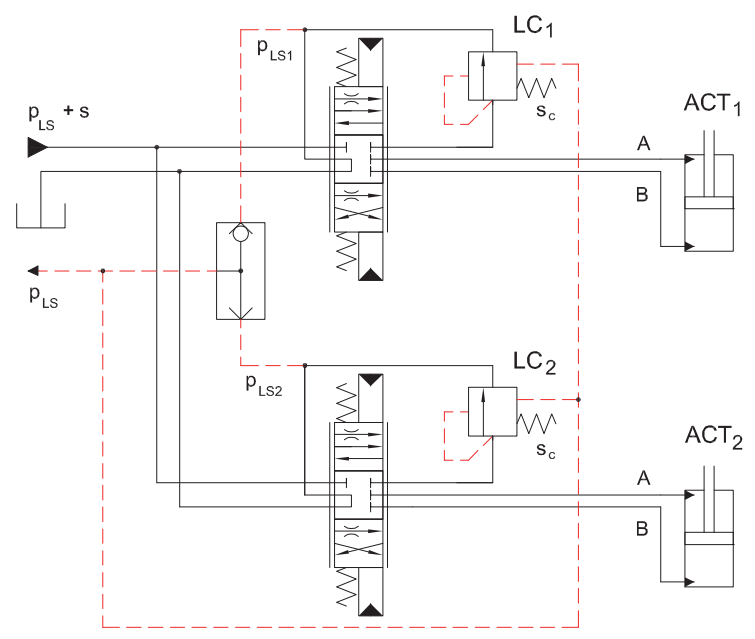

Fig. 1. Typical hydraulic scheme of the connections of the proportional valves with post-compensators in a circuit with two actuators. 
The aim of the LC is to maintain a constant pressure drop across the metering edge of the main spool, whose flow area is imposed by an electro-hydraulic device controlled by the operator. The flow rate at the outlet of the LC is directed towards the port A or B by means of a second passage through the main spool. The LC is maintained normally closed by a low-stiffness spring, with equivalent pressure setting $s_{c}$, and by the maximum load sensing signal $p_{\mathrm{LS}}$ that can be selected by a shuttle valve, as in the reported example, while the opening force is generated by the pressure downstream the metering edge of the main spool, which is maintained to the value $p_{\mathrm{LS}}+s_{c}$. Since upstream the metering edge the pressure is regulated by the load sensing control of the pump at the value $p_{\mathrm{LS}}+s$, where $s$ is the pump margin, the pressure drop across the metering edge is maintained equal to $s-s_{c}$.

The specific directional control valve used in the present study is reported in Fig. 2. The main spool is controlled by an electro-hydraulic device not shown in figure. When the valve is open, regardless of the working port fed, the flow rate passes through the circular notches of the main spool, is throttled by the local compensator and finally is directed to the port A or B.

The LS pilot signal is transferred in the spring side chamber of the LC through an annular groove on the casing and a radial hole in the spool. The flow area of the LC is generated by three couples of holes with different overlaps.

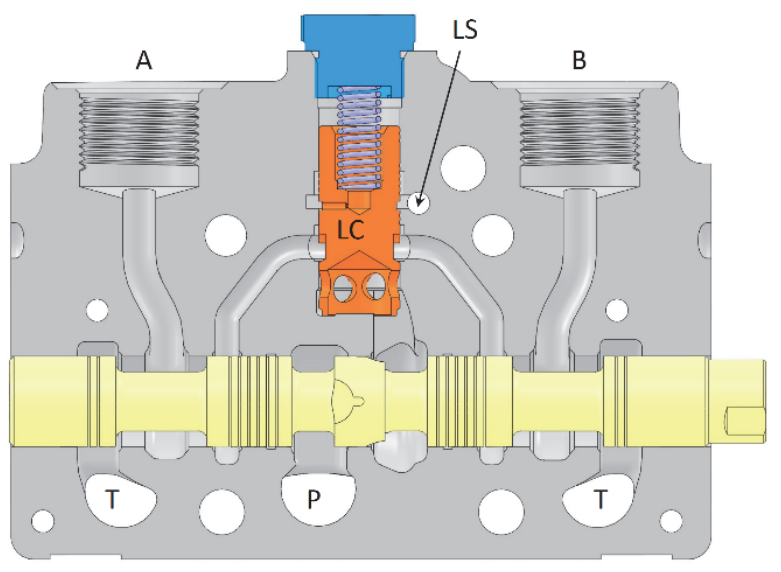

Fig. 2. View of the directional control valve used in the present study.

\section{Experimental facility}

The experimental tests were aimed at determining the pressure drop across the valve and the flow force acting on the main spool. The valve was tested without load with a direct connection between the ports A and B by means of a flexible pipe. A customized inlet block was designed for feeding the valve and for properly measuring the pressures. The position of the mobile components, main spool and local compensator, was maintained fixed. In particular, for the local compensator the LS port was connected to the T port, the spring was removed and substituted by a metal spacer for imposing the desired degree of opening. The flow rate was generated by a 119 $\mathrm{cc} / \mathrm{rev}$ variable displacement axial piston pump with absolute pressure limiter and was imposed at the port $\mathrm{P}$ by means of a two-port flow control valve. The flow rate was measured by a turbine flow meter Flo-Tech FSC-1000 with measuring range 11.5 - $227 \mathrm{~L} / \mathrm{min}$. The working fluid used in the test rig was an ISO VG 46 hydraulic oil.

In Fig. 3 a 3D drawing of the valve with a transparency view of half the inlet block is shown. Four absolute pressure transducers GS XPM5 were mounted on the inlet block. The transducers $P_{P}$, with range 0-100 bar, and $P_{T}$, with range 0-25 bar, were used for sensing the pressure in the perpendicular channels $\mathrm{P}$ and $\mathrm{T}$. For measuring the pressure at ports $\mathrm{A}$ and $\mathrm{B}$ two drillings were 
made on the housing of the valve in correspondence of two channels in the inlet block and two transducers with range 0-50 bar where mounted at the end of such channels (only $\mathrm{P}_{\mathrm{B}}$ is visible in figure).

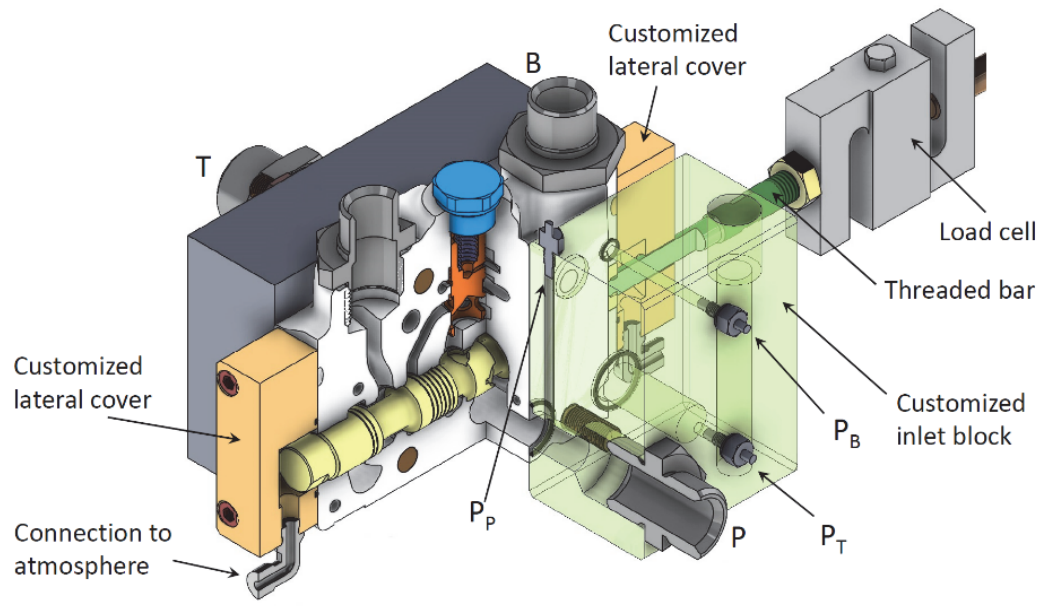

Fig. 3. Cutaway 3D drawing with the position of the transducers.

For the measurement of the flow force on the main spool, the electro-hydraulic control was removed and two covers were specifically manufactured. In order to avoid a pressure built-up on the lateral surfaces of the spool, the chambers were connected directly to the atmosphere by means of $90^{\circ}$ fittings used also for collecting the leakages. In Fig. 4 a photo of the entire measurement system is shown.

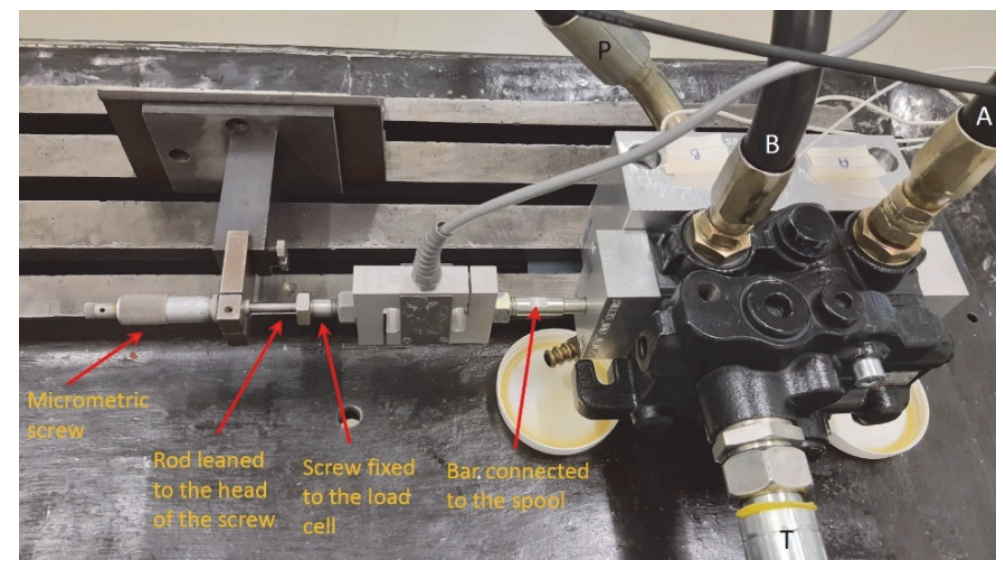

Fig. 4. Photo of the valve mounted on the test rig.

The right cover has a through hole for connecting the spool to a load cell Applied Measurements DBBE with reassuring range $0-50 \mathrm{~kg}$ by means of a rod threatened on both sides. On the opposite side the load cell is simply leaned against the rod of a micrometric screw that decides the position of the spool. When the valve is open the flow force pushes the load cell against the micrometric screw. This solution allows to test the valve only for the connection P-B and A-T, because with the opposite configuration the flow force would detach the load cell from the micrometric screw. However, this solution has the advantage to not generate any additional radial force that could increase the static friction and alter the measurement. 


\section{Simulation models}

\subsection{CFD model}

The CFD model of the valve was built with the commercial software FloEFD 2019.1 embedded in SolidEdge ${ }^{\circledR}$. The same tool has been successfully used by the authors for the simulation of a small control valve of a displacement control [17]. FloEFD discretizes the governing equations with the finite volume method and automatically recognizes as fluid volume the enclosed region of the CAD geometry, hence it is necessary to close all open ports by means of "lids". Since the pressure transducers of port B and A in the experimental facility measured pressures at the drillings' locations in the housing of the valve, a specific CAD was created in order to be able to impose boundary conditions according to experimental data.

The model geometry and an example of the computational grid is shown in Fig. 5 on the left. The basic mesh was realized with the automatic tool available in FloEFD. It was set the level of initial discretization together with the refinement criterion of advanced channel refinement. A ring part was superimposed to the assembly, but not considered in the definition of the fluid boundary, for defining a region with a finer grid in correspondence of the compensator's holes. Cylindrical regions instead were defined across the notches and all spool lands for the same purpose. It was so possible to obtain higher quality results about the forces on the lands and, on the notches, to guarantee enough cells across the flow area. Every created local mesh was characterized by a proper level of refinement and the characteristic number of cells across channels was imposed equal to 14 . Moreover, after one travel of calculation, which defines the number of iterations required for the propagation of a disturbance over the whole computational domain, the mesh was automatically refined in the areas where gradients were larger, as visible in Fig. 5 on the right.

All computational grids had approximately 3.5 million cells after the solution adaptive refinement. Simulations were performed on an eight core i7-9800X at $3.80 \mathrm{GHz}$ (8 physical cores used) and took about 5 hours each.

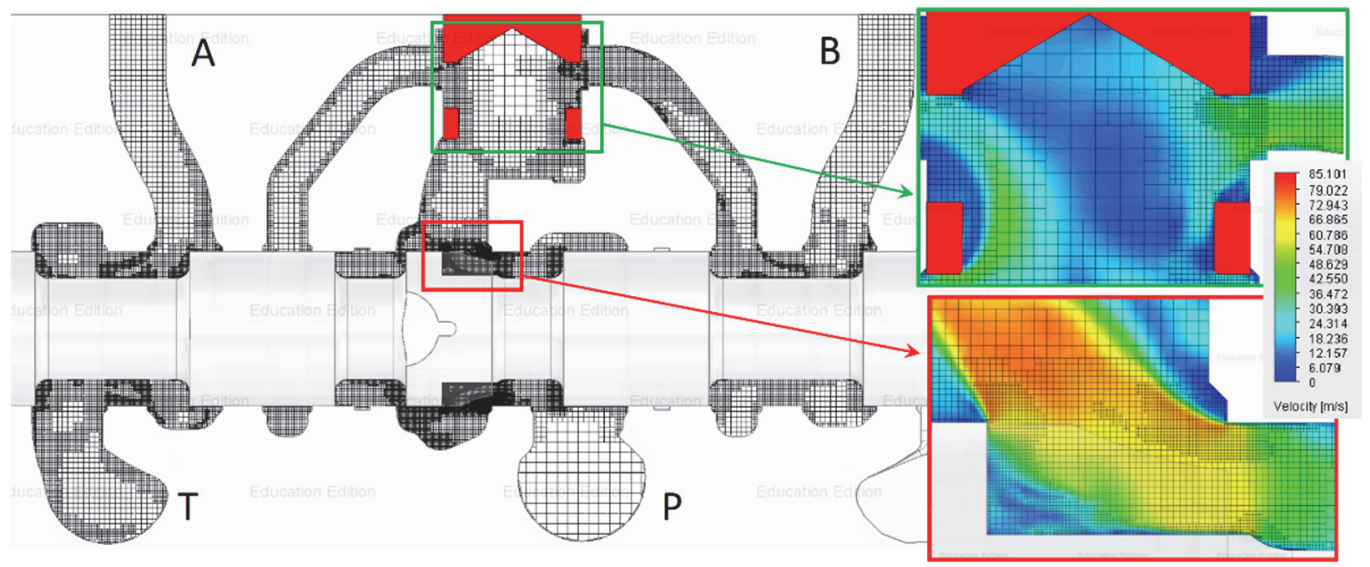

Fig. 5. CFD model with the details of the velocity field through the flow areas of the spools. Case with spool displacement of $8 \mathrm{~mm}$ and flow rate $150 \mathrm{~L} / \mathrm{min}$.

As boundary conditions the ingoing flow rate was set at the ports $\mathrm{P}$ and $\mathrm{A}$, while at the ports $\mathrm{B}$ and $\mathrm{T}$ the experimental pressure values were imposed. The output quantities were the pressures at port $\mathrm{P}$ and $\mathrm{A}$ and the total axial force of the main spool. Since there was no pressure on the 
lateral surfaces of the spool, the force calculated by the software is only the flow force that can be directly contrasted with the experimental value measured by the load cell.

The tests were performed with three positions of the main spool imposed by the micrometric screw, namely 6,7 and $8 \mathrm{~mm}$, at constant oil temperature of $40^{\circ} \mathrm{C}$. For each position of the spool 4-5 values of flow rate were imposed. In Fig. 6a the pressures at ports $\mathrm{P}$ and A are shown. As far as the pressure at port $\mathrm{A}$ is concerned, the value is in practice not affected by the spool position, since the flow area A-T through the land of the main spool is much larger than the flow area through the circular notches in the path P-B. For each position of the spool the flow rate was increased and decreased twice in order to acquire more times the same operating point for checking the test repeatability. The experimental points were fitted with a quadratic regression curve. In Fig. $6 b$ the flow force is shown.

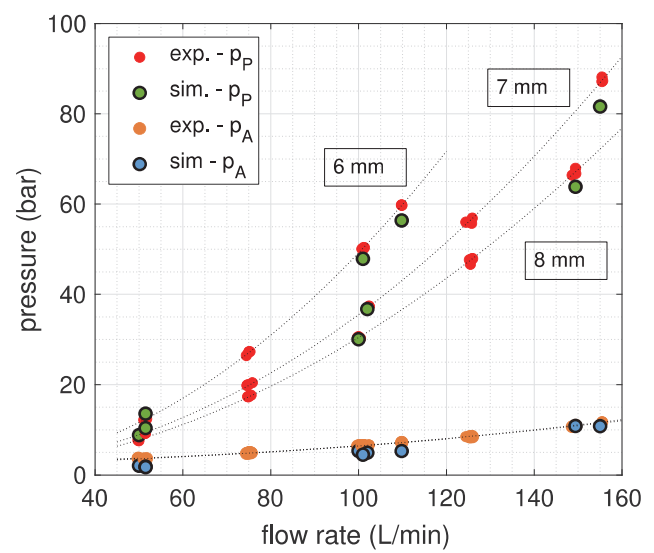

(a)

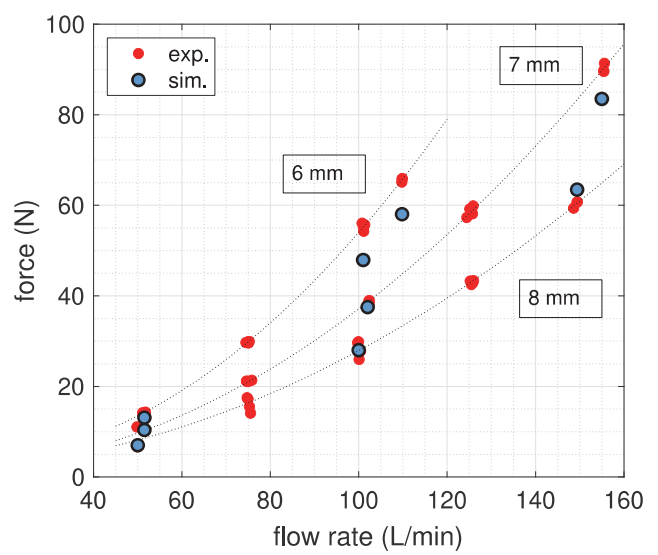

(b)

Fig. 6. (a) pressure at ports $\mathrm{P}$ and $\mathrm{A}$ and (b) flow force vs. the flow rate for three spool positions. Comparison between CFD model and experimental data fitted with a quadratic curve (dotted line).

\subsection{Lumped parameter model}

The model in the Simcenter Amesim environment of the valve is shown in Fig. 7, together with the lines representing the experimental facility. The spool position is imposed by means of the element 1 and a flow rate ramp at the inlet port of the valve from 0 to $160 \mathrm{~L} / \mathrm{min}$ is defined by an ideal flow source (element 2). In order to reproduce the same working conditions of the tested valve, the restrictors representing the discharge lines (elements 3 and 4) were characterized by a pressure drop - flow rate curve obtained from experimental data. Similar characterization has been done for the restrictor 5, which represents the pipe between ports B and A. The tuning of the model started from the elements representing the local compensator (group of elements 6). The discharge coefficients have been modified in order to obtain, in chamber 7, a pressure value close to the one calculated by the CFD software, approximately 35 bar with $150 \mathrm{~L} / \mathrm{min}$. With a discharge coefficient of 0.8 this target was obtained.

After defining the downstream pressure of the notch, the tuning of the element 8 has been done in order to obtain the same inlet pressure measured experimentally. 


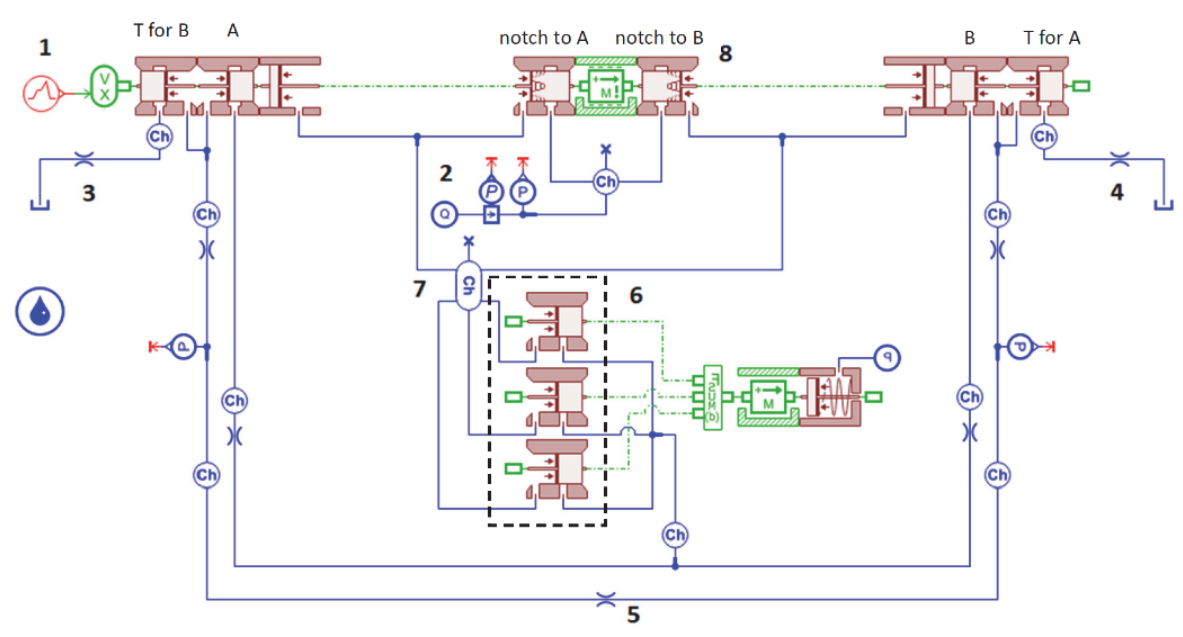

Fig. 7. Model of the valve in Simcenter Amesim.

The pressure at port $\mathrm{P}$ with the flow coefficient equal to 0.48 is shown in Fig. 9a for the three different openings of the spool. After defining a proper value for the discharge coefficient, the jet force coefficient of the notch element was tuned according to experimental data. Such a parameter represents a correction factor that multiplies the theoretical equation coming from the conservation of the fluid momentum. By imposing this coefficient equal to 1.03, the flow forces obtained are shown in Fig. $9 \mathrm{~b}$.

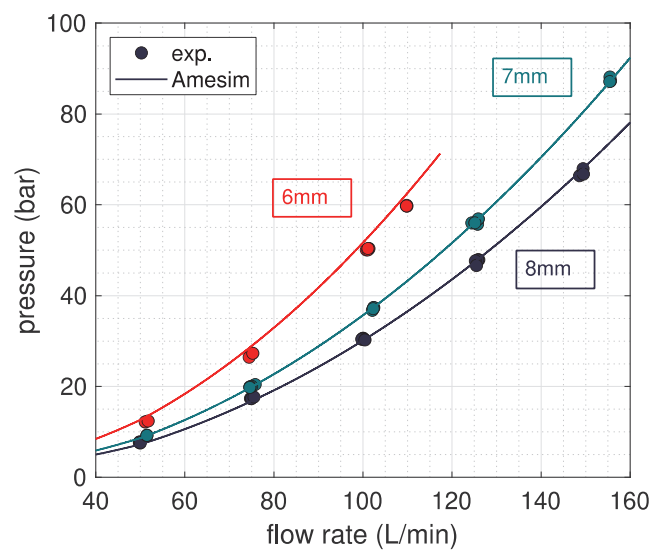

(a)

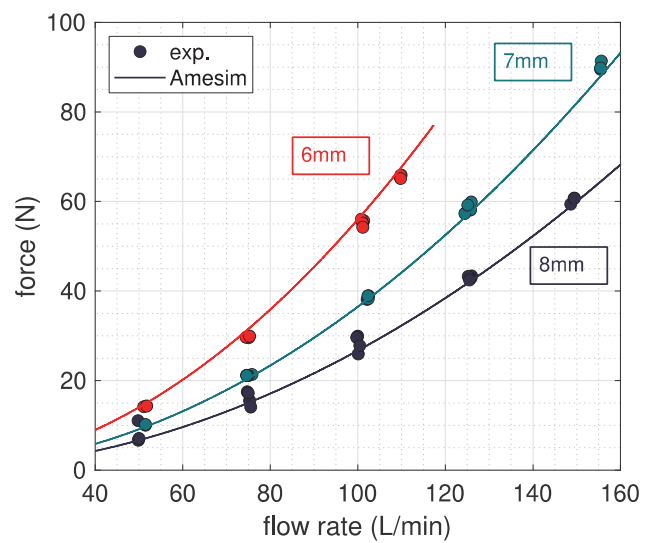

(b)

Fig. 8. (a) pressure at port $\mathrm{P}$ and (b) flow force vs. the flow rate for three spool positions. Comparison between lumped parameter model and experimental data.

\section{Discussion}

The CFD model is able to reproduce very well the pressure drops inside the valve, moreover also the flow force, that usually is the most complex quantity to be correctly simulated, despite an underestimation at smaller opening of the valve, is reproduced quite well. The validation in different operating conditions has demonstrated that the CFD model is reliable enough to be used as optimization tool. In fact, the validation of only the pressure drop is a condition necessary but not sufficient for stating that the model will be also able to predict the flow force, since such a 
force is a consequence of the pressure field around the entire spool and not only in local regions across the minimum flow areas. In this study a direct validation of the flow force has been performed, hence the model can be used with a good degree of confidence for evaluating the effectiveness of a geometric modification for reducing the flow force.

For this purpose, the maximum spool position of $8 \mathrm{~mm}$ was considered, and the distance between the land of the notches and its opposite was varied with respect to the original value of $9.36 \mathrm{~mm}$. Two examples of what has been modified are reported in Fig. 8, where the maximum distance analyzed of $18 \mathrm{~mm}$ and the minimum one of $6.1 \mathrm{~mm}$ are shown. With these geometrical variations simulations were performed by imposing $150 \mathrm{~L} / \mathrm{min}$ of inlet flow rate. The results in terms of inlet pressure and flow force of all configurations were compared as shown in Fig. 9. By reducing the land distance, the flow force decreases thanks to the variation of the pressure profile due to the increment of the fluid velocity on the land opposed to the notches. The drawback is the increment of the inlet pressure due to the reduced flow area, however it is possible to observe that a reduction of the land distance of a couple of millimeters allows a reduction of the flow force of more than $20 \%$ with an increment of the pressure drop of just $5 \%$.
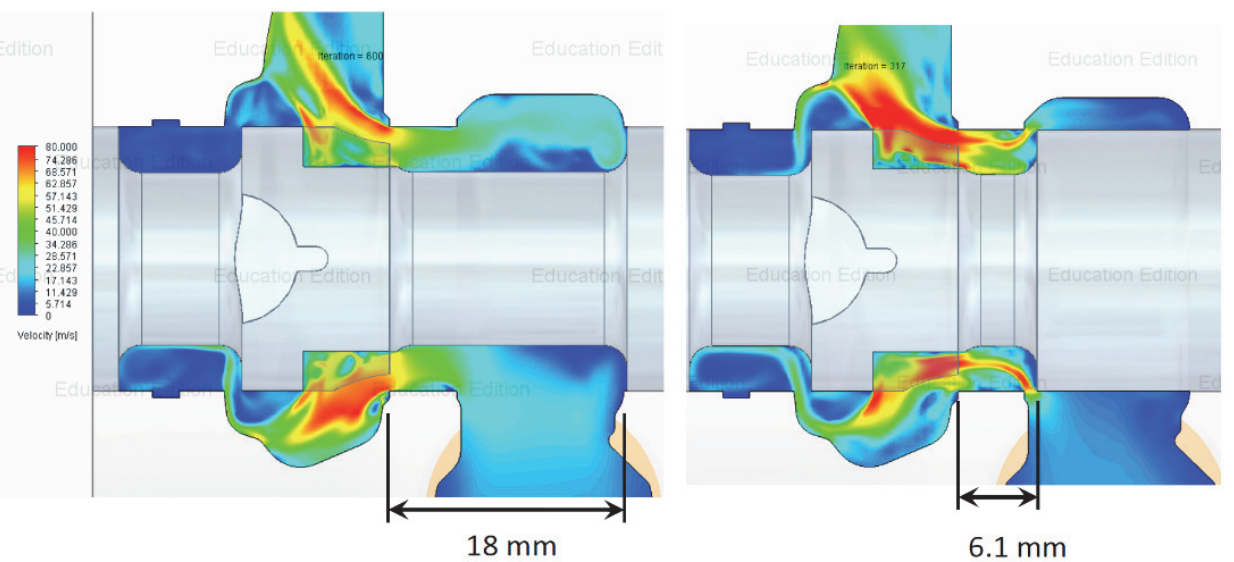

Fig. 8. Fluid velocity field with two different distances between the lands of the spool.

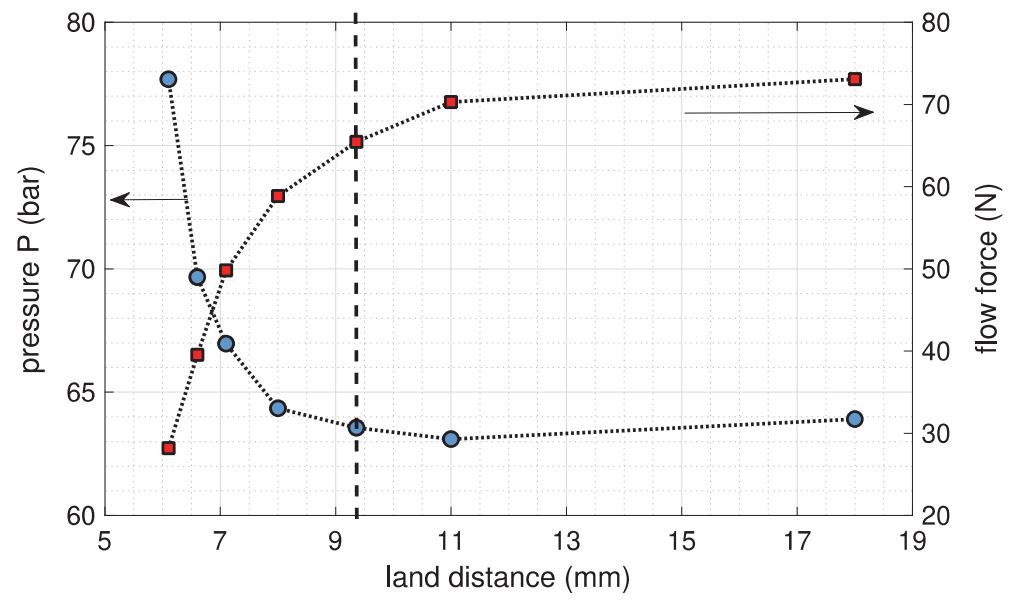

Fig. 9. Pressure at port $\mathrm{P}$ and flow force as function of the land distance with $150 \mathrm{~L} / \mathrm{min}$. The dashed vertical line indicates the original distance $(9.36 \mathrm{~mm})$. 
It can be observed that such a type of evaluation cannot be performed using the lumped parameter model. In fact, even if the force calculated with the theoretical equation implemented in Simcenter Amesim gives results very close to the experimental values, since the correction factor is about 1 , the values of the discharge coefficients are quite different from the default value 0.7. As a consequence, the optimal value of the land distance could not have been estimated, due to the uncertainty on the assessment of the real pressure drop. However, once tuned on a specific geometry, the $0 \mathrm{D}$ model can be used for simulating with a lumped parameter approach a more complex hydraulic circuit.

\section{Conclusions}

In a directional control valve, two aspects must be considered: the internal local fluid resistances that increase the dissipated power, and the flow force that influences the size of the spool positioning device. The optimization of the component needs a reliable tool for limiting the number of geometrical configurations that must be tested experimentally. A typical technique for reducing the flow forces is to generate a pressure drop on the opposite land of the spool in order to create a counterbalancing force. However, a compromise between the force reduction and the increment of the overall pressure drop across the valve must be reached. The use of a lumped parameter model has the drawback that some coefficients are function of the geometry, therefore the tuning on a specific experimental test does not guarantee that the same coefficients can be used to study different geometric configurations. From this point of view, a CFD model is more suitable, since it can consider more complex 3D effects. In this paper the effectiveness of a userfriendly CAD-embedded CFD software has been tested rigorously and good results have been obtained for both the pressure drop and the flow force.

\section{References}

1. P. Casoli, F. Scolari, T. Minav, M. Rundo, Comparative energy analysis of a load sensing system and a zonal hydraulics for a 9-tonne excavator. Actuators 9(2) (2020). DOI: 10.3390/ACT9020039.

2. D. Padovani, M. Rundo, G. Altare, The working hydraulics of valve-controlled mobile machines: Classification and review. J. Dyn. Syst. Meas. Control 142(7) (2020). DOI: 10.1115/1.4046334.

3. P. Casoli, A. Anthony, L. Ricco, Modeling simulation and experimental verification of an excavator hydraulic system - Load sensing flow sharing valve model. SAE Technical Paper (2012). DOI: 10.4271/2012-01-2042.

4. F. Pintore, A. Benevelli, M. Borghi, B. Zardin, R. Morselli, F. Belluzzi, Modelling and simulation of the hydraulic circuit of an agricultural tractor. FPNI Ph.D Symp. Fluid Power (2014). DOI: 10.1115/FPNI2014-7848.

5. P. Casoli, L. Riccò, F. Campanini, A. Lettini, C. Dolcin, Mathematical model of a hydraulic excavator for fuel consumption predictions. ASME/BATH Symp. Fluid Power Motion Control (2015). DOI: 10.1115/FPMC2015-9566.

6. A. Corvaglia, G. Altare, R. Finesso, M. Rundo, Computational Fluid Dynamics Modelling of a Load Sensing Proportional Valve. ASME-JSME-KSME Jt. Fluids Eng. Conf. (2019).

DOI: 10.1115/AJKFluids2019-4708. 
7. E. Frosina, G. Marinaro, A. Senatore, M. Pavanetto, Numerical and experimental investigation for the design of a directional spool valve. Energy Procedia 148: 274-280 (2018). DOI: 10.1016/j.egypro.2018.08.078.

8. M. Olivetti, F.G. Monterosso, G. Marinaro, E. Frosina, P. Mazzei, Valve geometry and flow optimization through an automated DOE approach. Fluids 5(1) (2020). DOI: 10.3390/fluids5010017.

9. R. Finesso, M. Rundo, Numerical and experimental investigation on a conical poppet relief valve with flow force compensation, Int. Journal of Fluid Power 18(2): 111-122 (2017). DOI: 10.1080/14399776.2017.1296740.

10. M. Rundo, G. Altare, Comparison of Analytical and Numerical Methods for the Evaluation of the Flow Forces in Conical Poppet Valves with Direct and Reverse Flow. Energy Procedia 126: 1107-1114 (2017). DOI: DOI: 10.1016/j.egypro.2017.08.261.

11. A. Fornaciari, B. Zardin, M. Borghi, M. Ceriola, Analysis of the flow force compensation in relief valves with conical poppet. BATH/ASME Symp. Fluid Power Motion Control (2020). DOI: 10.1115/FPMC2020-2759.

12. E. Lisowski, W. Czyzycki, J. Rajda, Three dimensional CFD analysis and experimental test of flow force acting on the spool of solenoid operated directional control valve. Energy Convers. Manag. 70: 220-229 (2013). DOI: 10.1016/j.enconman.2013.02.016.

13. R. Amirante, L.A. Catalano, P. Tamburrano, The importance of a full 3D fluid dynamic analysis to evaluate the flow forces in a hydraulic directional proportional valve. Eng. Comput. 31(5): 898-922 (2014). DOI: 10.1108/EC-09-2012-0221.

14. E. Lisowski, G. Filo, J. Rajda, Analysis of Flow forces in the initial phase of throttle gap opening in a proportional control valve. Flow Meas. Instrum. 59: 157-167 (2018). DOI: 10.1016/j.flowmeasinst.2017.12.011.

15. R.S. Jackson, K.J. Cassaidy, M.M. Belger, A.R. Kokemoor, CFD simulation and experimental investigation of steady state flow force reduction in a hydraulic spool valve with machined back angles. ASME/BATH Symp. Fluid Power Motion Control (2017). DOI: 10.1115/FPMC2017-4323.

16. E. Frosina, A. Senatore, D. Buono, K.A. Stelson, A Mathematical Model to Analyze the Torque Caused by Fluid-Solid Interaction on a Hydraulic Valve. J. Fluids Eng. 138(6) (2016). DOI: 10.1115/1.4032295.

17. M. Rundo, P. Fresia, CFD Analysis of a Pressure Compensator for Variable Displacement Pumps, 22 ${ }^{\text {nd }}$ Australasian Fluid Mechanics Conference (2020). DOI: 10.14264/44f591d. 